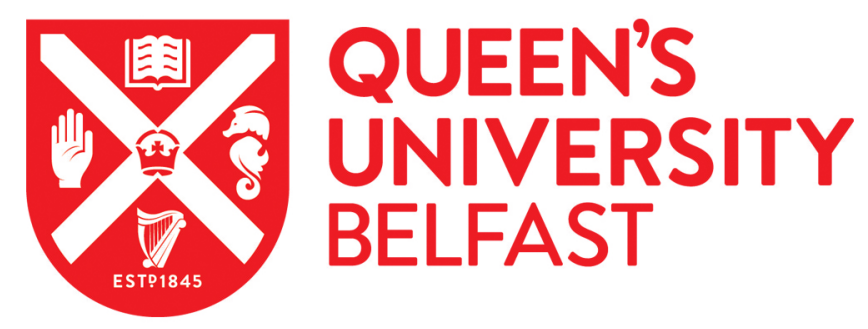

\title{
Timing and climate forcing of volcanic eruptions for the past 2,500 years
}

Sigl, M., Winstrup, M., McConnell, J. R., Welten, K. C., Plunkett, G., Ludlow, F., Büntgen, U., Caffee, M., Chellman, N., Dahl-Jensen, D., Fischer, H., Kipfstuhl, S., Kostick, C., Maselli, O. J., Mekhaldi, F., Mulvaney, R., Muscheler, R., Pasteris, D. R., Pilcher, J. R., ... Woodruff, T. E. (2015). Timing and climate forcing of volcanic eruptions for the past 2,500 years. Nature, 523(7562), 543-549. https://doi.org/10.1038/nature14565

\section{Published in:}

Nature

\section{Document Version:}

Peer reviewed version

Queen's University Belfast - Research Portal:

Link to publication record in Queen's University Belfast Research Portal

\section{Publisher rights}

@2015 Macmillan Publishers Limited. All rights reserved

The final version of this article may be found at http://www.nature.com/nature/journal/vaop/ncurrent/full/nature14565.html

\section{General rights}

Copyright for the publications made accessible via the Queen's University Belfast Research Portal is retained by the author(s) and / or other copyright owners and it is a condition of accessing these publications that users recognise and abide by the legal requirements associated with these rights.

Take down policy

The Research Portal is Queen's institutional repository that provides access to Queen's research output. Every effort has been made to ensure that content in the Research Portal does not infringe any person's rights, or applicable UK laws. If you discover content in the Research Portal that you believe breaches copyright or violates any law, please contact openaccess@qub.ac.uk. 
$8 \quad{ }^{1}$ Desert Research Institute, Nevada System of Higher Education, Reno, NV 89512, USA

$9{ }^{2}$ now at Laboratory of Radiochemistry and Environmental Chemistry, Paul Scherrer Institut, 5232 Villigen, 10 Switzerland

$11{ }^{3}$ Department of Earth and Space Sciences, University of Washington, Seattle, WA 98195, USA

$12{ }^{4}$ Space Sciences Laboratory, University of California, Berkeley, CA 94720, USA

$13{ }^{5}$ School of Geography, Archaeology \& Palaeoecology, Queen's University Belfast, Belfast BT7 1NN, UK

$14{ }^{6}$ Yale Climate \& Energy Institute, and Department of History, Yale University, New Haven, CT 06511, USA

$15{ }^{7}$ Swiss Federal Research Institute WSL, 8903 Birmensdorf, Switzerland

$16{ }^{8}$ Oeschger Centre for Climate Change Research, University of Bern, 3012 Bern, Switzerland

$17{ }^{9}$ Global Change Research Centre AS CR, 60300 Brno, Czech Republic

$18{ }^{10}$ Department of Physics, Purdue University, West Lafayette, IN 47907, USA

$19{ }^{11}$ Department of Earth, Atmospheric, and Planetary Sciences, Purdue University, West Lafayette, IN 47907,

20 USA

$21{ }^{12}$ Centre for Ice and Climate, Niels Bohr Institute, University of Copenhagen, 2100 Copenhagen, Denmark

${ }^{13}$ Climate and Environmental Physics, University of Bern, 3012 Bern, Switzerland

${ }^{14}$ Alfred-Wegener-Institut Helmholtz-Zentrum für Polar- und Meeresforschung, 27570 Bremerhaven, Germany

${ }^{15}$ Department of History, The University of Nottingham, Nottingham NG7 2RD, UK

${ }^{16}$ Department of Geology, Quaternary Sciences, Lund University, 22362 Lund, Sweden

$26{ }^{17}$ British Antarctic Survey, Natural Environment Research Council, Cambridge, CB3 OET, UK

$27{ }^{18}$ The Laboratory of Tree-Ring Research, University of Arizona, Tucson, AZ 85721, USA 
Volcanic eruptions contribute to climate variability, but quantifying these contributions has been limited by inconsistencies in the timing of atmospheric volcanic aerosol loading determined from ice cores and subsequent cooling from climate proxies such as tree rings. Using new records of atmospheric aerosol loading developed from high-resolution, multi-parameter measurements from an array of Greenland and Antarctic ice cores as well as distinctive age markers to constrain chronologies, we resolve these inconsistencies. Here we show that large eruptions in the tropics and high latitudes were primary drivers of interannual-to-decadal temperature variability in the Northern Hemisphere during the past 2,500 years. Overall, cooling was proportional to the magnitude of volcanic forcing and persisted for up to ten years after some of the largest eruptive episodes. Our revised timescale now firmly implicates volcanic eruptions as catalysts in the major 6th century pandemics, famines, and socioeconomic disruptions in Eurasia and Mesoamerica while allowing multi-millennium quantification of climate response to volcanic forcing.

Volcanic eruptions are primary drivers of natural climate variability - as sulfate aerosol injections into the stratosphere shield the Earth's surface from incoming solar radiation, leading to short-term cooling at regional-to-global scales ${ }^{1}$. Temperatures during the past 2,000 years have been reconstructed at regional $\left.\right|^{2}$, continental ${ }^{3}$, and global scales ${ }^{4}$ using proxy information from natural archives. Tree-ring-based proxies provide the vast majority of climate records from mid- to highlatitude regions of (predominantly) the Northern Hemisphere $(\mathrm{NH})$, whereas ice-core records (e.g., $\left.\delta^{18} \mathrm{O}\right)$ represent both polar regions ${ }^{3}$. Climate forcing reconstructions for the Common Era (CE) including solar (e.g., $\left.{ }^{10} \mathrm{Be}\right)^{5}$ and volcanic (e.g., sulfate) ${ }^{6,7}$ activity - mostly derive from ice-core proxies. Any attempt to attribute reconstructed climate variability to external volcanic forcing - and distinguish between response, feedback, and internal variability of the climate system - requires icecore chronologies that are synchronous with those of other climate reconstructions. In addition,

52 multi-proxy climate reconstructions ${ }^{2-4}$ derived from ice cores and other proxies such as tree rings will 53 have diminished high-to-mid-frequency amplitudes if the individual climate records are on different 54 timescales. Magnitudes and relative timing of simulated $\mathrm{NH}$ temperature response to large volcanic 
eruptions are in disagreement with reconstructed temperatures obtained from tree rings ${ }^{8,9}$, but it is

56 unclear to what extent this model/data mismatch is caused by limitations in temperature

57 reconstructions, volcanic reconstructions, or implementation of aerosol forcing in climate models ${ }^{9-11}$.

58 The hypothesis of chronological errors in tree-ring-based temperature reconstructions ${ }^{8,9}$ offered to 59 explain this model/data mismatch has been tested and widely rejected ${ }^{11-14}$, while new ice-core 60 records have become available providing different eruption ages ${ }^{15,16}$ and more precise estimates of 61 atmospheric aerosol mass loading ${ }^{17}$ than previous volcanic reconstructions. Using documented ${ }^{18}$ and $^{-1}$ 62 previous ice-core-based eruption ages ${ }^{16}$, strong summer cooling following large volcanic eruptions 63 has been recorded in tree-ring-based temperature reconstructions during the $2^{\text {nd }}$ millennium CE with 64 a one-to-two year lag similar to that observed in instrumental records after the 1991 Pinatubo 65 eruption ${ }^{19}$. An apparent seven-year delayed cooling observed in individual tree-ring series relative to 66 Greenland ice-core acidity peaks during the $1^{\text {st }}$ millennium $C E$, however, suggests a bias in existing 67 ice-core chronologies ${ }^{20,21}$. Using published ice-core chronologies, we also observed a seven-year offset between sulfate deposition in North Greenland and the start of tree-ring growth reduction in a composite of five multi-centennial tree-ring summer temperature reconstructions ("N-Tree") from the NH between 1 and 1000 CE (Methods), whereas tree-ring response was effectively immediate for eruptions occurring after 1250 CE (Fig. 1a).

Precise time marker across hemispheres. Independent age markers to test the accuracy of tree-ring and ice-core chronologies recently have become available with the detection of abrupt enrichment events in the ${ }^{14} \mathrm{C}$ content of tree rings. Rapid increases of atmospheric ${ }^{14} \mathrm{C}$ were first identified in individual growth increments of cedars from Japan between 774 and 775 CE $^{22}$ and between 993 and $994 \mathrm{CE}^{23}$. The presence and timing of the event in $775 \mathrm{CE}$ (henceforth, 775 event) has been reproduced by all radiocarbon measurements performed on tree rings at annual (or higher) resolution - including tree cores from Germany ${ }^{24}$, the Alps ${ }^{12}$, the Great Basin ${ }^{25}$ (USA), and Siberia ${ }^{25}$. Recent identification of the same 775 CE event in kauri wood samples from New Zealand in the Southern Hemisphere (SH) demonstrates the global extent of the rapid ${ }^{14} \mathrm{C}$ increase and provides 
81 further constraints on the event's exact timing (March $775 \pm 6$ months) due to the asynchronous SH

82 growing season ${ }^{26}$. While the cause of the 775 and 994 events is still debated ${ }^{22,24,27}$, we expect that

83 they might also produce an excess of cosmogenic ${ }^{10} \mathrm{Be}$ through the interaction of high-energy

84 particles with atmospheric constituents ${ }^{28,29}$. Since both of these radionuclides are incorporated

85 rapidly into proxy archives via aerosol deposition $\left({ }^{10} \mathrm{Be}\right.$ in ice cores) and photosynthesis $\left({ }^{14} \mathrm{CO}_{2}\right.$ in tree

86 rings), isotopic anomalies caused by these extraterrestrial events provide a global age marker to

87 directly link ice-core records to tree-ring chronologies ${ }^{27}$. The latter serve as an absolute and precise

88 age marker, verified (at least since $775 \mathrm{CE}$ ) by the coherence of the rapid increase in ${ }^{14} \mathrm{C}$ in all tree-

rings records for which high-resolution radiocarbon analyses were performed, including those

speculated to be at risk of missing rings ${ }^{8}$. We measured ${ }^{10} \mathrm{Be}$ concentrations at approximately annual resolution in four ice cores - NEEM-2011-S1, TUNU2013, and NGRIP in Greenland, and the West Antarctic Ice Sheet Divide Core (WDC) - over depth ranges encompassing the year 775 as dated in existing ice-core chronologies in order to provide a direct, physically-based test of any dating bias in these chronologies (Fig. 1, Extended Data Fig. 1, Methods, Supplementary Data S1). Both polar ice sheets contain ${ }^{10} \mathrm{Be}$ concentrations exceeding the natural background concentration $(>150 \% ; 6 \sigma)$ for one-to-two consecutive years, compatible with the $775 \mathrm{CE}$ event observed in tree rings. Using the original ice-core age models ${ }^{16,30}$, the ages of the ${ }^{10}$ Be maxima in NEEM-2011-S1, NGRIP, and WDC are $768 \mathrm{CE}$, offset by 7 years from the tree-ring event. A further ${ }^{10} \mathrm{Be}$ anomaly measured in NEEM-2011S1 at $987 \mathrm{CE}$, compatible with the $994 \mathrm{CE}$ event in tree rings, suggests a chronological offset was present by the end of the first millennium CE (Fig. 1). Several different causes may have contributed to the offset (see a summary in the Methods section), among which is the use of a previous dating constraint $^{30}$ for Greenland where volcanic fallout in the ice was believed to indicate the historic (79 CE) eruption of Vesuvius.

Revised ice-core chronologies. Given the detection of a bias in existing ice-core chronologies, we developed new timescales prior to the 1257 Samalas eruption ${ }^{31}$ using highly resolved, multi- 
used the StratiCounter program, an automated, objective, annual-layer detection method based on Hidden Markov Model (HMM) algorithms ${ }^{32}$ (Methods). For NEEM-2011-S1, obtained confidence intervals for the layer counts allowed us to improve the dating further by constraining the timescale using the $775 \mathrm{CE}{ }^{10} \mathrm{Be}$ anomaly and three precisely dated observations of post-volcanic aerosol loading of the atmosphere (Fig. 2, Extended Data Tables 1-3, Methods, Supplementary Data S2). We evaluated the accuracy of our new chronologies ("WD2014" for WDC and "NS1-2011" for NEEM) by comparison to (1) an extensive database of historical volcanic dust veil observations (Extended Data Fig. 2, Methods, Supplementary Data S2), (2) ice-core tephra evidence (Methods), and (3) the 994 CE event (Methods, Fig. 2). Using the new timescales, we found large sulfate signals in Greenland (e.g. 682, 574, 540 CE) between 500 and 2000 CE that frequently occurred within \pm 1 year from comparable - and independently dated - signals in Antarctica. These bipolar signals can now be confidently attributed to large tropical eruptions (Fig. 2). Back to 400 BCE, other large sulfate peaks (e.g., 44 BCE) were synchronous to within \pm 3 years (Fig. 2). We conclude that the revised ice-core timescales are accurate to within less than \pm 5 years during the past 2,500 years based on combined evidence from radionuclides, tree rings, tephra analyses, and historical accounts. Compared to the previous chronologies, age models differ prior to 1250 CE by up to 11 years (GICC05, Greenland) and 14 years (WDC06A-7, Antarctica) (Extended Data Fig. 3).

History of volcanic forcing. Employing our revised timescales and new high-resolution, ice-core sulfur measurements, we developed an extended reconstruction of volcanic aerosol deposition since early Roman times for both polar ice sheets from which we then estimated radiative forcing using established transfer functions ${ }^{15}$ (Fig. 3, Methods, Supplementary Data S3-S5). This forcing series is characterized by improved dating accuracy, annual resolution, and a larger number of ice-core records in the Antarctic ice-core sulfate composite ${ }^{17}$ than previous reconstructions ${ }^{6,7}$. It spans 2,500 years, allowing investigation of climate-volcano linkages more accurately and earlier than with previous reconstructions. It also provides a perspective on volcanic influences during major historical epochs, such as the growth of Roman imperial power and subsequent decline of the migration 
133 period in Europe - times of (1) demographic and economic expansion as well as relative societal 134 stability and (2) political turmoil and population instability, respectively ${ }^{33}$. With improved dating and 135 lower volcanic-sulfate detection limits from the Antarctic array ${ }^{17}$, we were able to detect, estimate, and attribute volcanic aerosol loading and forcing from 283 individual eruptive events during this period (Fig. 3). We attributed about $50 \%$ to mid-to-high latitudes $\mathrm{NH}$ sources, while 81 were attributed to tropical eruptions (having synchronous sulfate deposition on both polar ice sheets). These tropical volcanic eruptions contributed $64 \%$ of total volcanic forcing throughout the period, with five events exceeding the sulfate loading from Tambora, 1815 (Fig. 3, Extended Data Table 4). Events in 426 BCE and 44 BCE rival the great 1257 CE Samalas eruption (Indonesia) as the largest sulfate producing eruptions during this time. These two earlier events have not been widely regarded as large tropical eruptions with potential for strong climate impact ${ }^{20}$, due to the lack of complete and synchronized sulfate records from Greenland and Antarctica. We base the claim that these two eruptions were tropical in origin and caused significant radiative perturbations on the observation that ice cores from Greenland and Antarctica record coeval (within their respective age uncertainties) and exceptionally high volcanic sulfate concentrations. Both these events were followed by strong and persistent growth reduction in tree-ring records ${ }^{34}$ (Fig. 2) as typically observed after large tropical eruptions during the Common Era (Fig. 3).

Post-volcanic summer cooling. Superposed epoch analyses (Methods) performed on the "N-Tree" composite record centered on the largest volcanic signals between 500 BCE and 1250 CE as well as between 1250 and 2000 CE, show a clear post-volcanic cooling signal. For both periods, maximum tree-ring response lagged the date of initial increase of sulfate deposition by one year (Fig. 2), consistent with the response observed if using only historically documented eruptions with secure dating for the past 800 years $^{18}$. The sharp and immediate (i.e., $\leq 1$ year lag) response of tree growth to the ice-core volcanic signal throughout the past 2,500 years further corroborates the accuracy of our new ice-core timescales (Extended Data Fig. 4). Of the 16 most negative tree-growth anomalies (i.e., coldest summers) between 500 BCE and $1000 \mathrm{CE}, 15$ followed large volcanic signals - with the 
four coldest (43 BCE, 536, 543, and 627 CE) occurring shortly after several of the largest events

160 (Extended Data Tables 4, 5). Similarly, the coldest summers in Europe during the Common Era ${ }^{3}$ were associated with large volcanic eruptions (Extended Data Table 5). Reduced tree growth after volcanic eruptions also was prominent in decadal averages of the "N-Tree" composite. All 16 decades with the most reduced tree growth for our 2,500-year period followed large eruptions (Fig. 3, Extended Data Table 5). In many cases, such as the coldest decade from 536 to $545 \mathrm{CE}^{3}$, sustained cooling was associated with the combined effect of several successive volcanic eruptions.

Strong post-volcanic cooling was not restricted to tropical eruptions; it also followed $\mathrm{NH}$ average of the 19 largest CE tropical eruptions, however, the $\mathrm{NH}$-only eruptions did not give rise to any significant long-term cooling effect (Fig. 4). Persistence of implied post-volcanic cooling following the largest tropical eruptions is strongly expressed in temperature reconstructions based on treering width measurements (e.g., those from the Alps), with recovery times of more than 10 years. Persistent cooling, with temperature reduction significantly below the pre-eruption baseline for six consecutive years, also is observed in temperature reconstructions based on maximum latewood density (e.g., those from Northern Scandinavia), the preferred proxy to quantify volcanic cooling contributions on climate due to less marked biological memory effects ${ }^{35}$ (Fig. 4). These findings indicate that eruption-induced climate anomalies following large tropical eruptions may last longer than is indicated in many climate simulations $(<3-5 \text { years })^{9,36,37}$ and that potential positive feedbacks initiated after large tropical eruptions (e.g., sea-ice feedbacks) may not be adequately represented in climate simulations $^{38,39}$. The five-year averaged (lag 0 to lag 4 years) cooling response over three $\mathrm{NH}$ regions (Methods) following the 19 largest CE tropical eruptions was $-0.6 \pm 0.2{ }^{\circ} \mathrm{C}(2$ standard error of the mean (SEM)), that of large $\mathrm{NH}$ eruptions was $-0.4 \pm 0.4{ }^{\circ} \mathrm{C}$ with strongest cooling induced in the high latitudes. Overall, cooling was proportional to the magnitude of volcanic forcing, with stratospheric sulfate loading exceeding that of Tambora inducing the strongest response of $-1.1 \pm$ $0.6{ }^{\circ} \mathrm{C}$ (Figs. 3, 4). 
Global climate anomalies in 536-550 CE. Our new dating allowed us to clarify long-standing debates concerning the origin and consequences of the severe and apparently global climate anomalies observed from c.536-550 CE, which began with recognition of the "mystery cloud" of $536 \mathrm{CE}^{40}$ observed in the Mediterranean basin. Under previous ice-core dating, it has been argued that this dust veil corresponded to an unknown tropical eruption dated 533-534 CE $( \pm 2)^{41}$. Using our revised timescales, we found at least two large volcanic eruptions around this period (Fig. 5). A first apparently $\mathrm{NH}$, eruptive episode in 535 or early $536 \mathrm{CE}$ - injected large amounts of sulfate and ash into the atmosphere. Geochemistry of tephra filtered from the NEEM-2011-S1 ice core at a depth corresponding to $536 \mathrm{CE}$ indicated multiple North American volcanoes as likely candidates for a combined volcanic signal (Extended Data Fig. 5, Methods, Supplementary Data S5). Historical observations (Extended Data Table 3) identified atmospheric dimming as early as March 24, 536, lasting up to 18 months. The summer of $536 \mathrm{CE}$ appeared exceptionally cold in all tree-ring reconstructions in the extra-tropical NH from N-America ${ }^{34}$, over Europe ${ }^{35,42,43}$ to Asia ${ }^{44}$. Depending upon reconstruction method, European summer temperatures in $536 \mathrm{CE}$ dropped $1.6-2.5^{\circ} \mathrm{C}$ relative to the previous 30-year average ${ }^{3}$. A second eruptive episode in 539 or $540 \mathrm{CE}$, identified in both Greenland and Antarctica ice-core records and hence likely tropical in origin, resulted in up to $10 \%$ higher global aerosol loading than the Tambora 1815 eruption reconstructed from our bipolar sulfate records. Summer temperatures consequently dropped again, by $1.4-2.7^{\circ} \mathrm{C}$ in Europe in 541 $\mathrm{CE}^{3}$, and cold temperatures persisted in the $\mathrm{NH}$ until almost $550 \mathrm{CE}^{3,33,34,42}$ (Figs. 2, 3, 5). This provides a notable environmental context to widespread famine and the great Justinian Plague 541543 CE that was responsible for decimating populations in the Mediterranean and potentially China ${ }^{45,46}$. While certain climatic conditions (e.g., wet summers) have been linked to plague outbreaks in the past ${ }^{47}$, a direct causal connection of these two large volcanic episodes and subsequent cooling to crop failures and outbreaks of famines and plagues is difficult to prove ${ }^{33}$. However, the exact delineation of two of the largest volcanic signals - with exceptionally strong and prolonged $\mathrm{NH}$ cooling; written evidence of famines and pandemics; as well as socio-economic 
211 decline observed in Mesoamerica ("Maya Hiatus"48), Europe, and Asia - supports the idea that the

212 latter may be causally associated with volcanically-induced climatic extremes.

Detailed study of major volcanic events during the $6^{\text {th }}$ century (Fig. 5) and an assessment of postvolcanic cooling throughout the past 2,500 years using stacked tree-ring records and regional temperature reconstructions (Fig. 4, Extended Data Fig. 4) demonstrated that large eruptions in the tropics and high latitudes were primary drivers of interannual-to-decadal NH temperature variability.

217 The new ice-core chronologies imply that previous multi-proxy reconstructions of temperature that 218 include ice-core records ${ }^{2-4}$ have diminished high-to-mid-frequency amplitudes and must be updated 219 to accurately capture the timing and full amplitude of paleoclimatic variability. By creating a volcanic 220 forcing index independent of but consistent with tree-ring-indicated cooling, we provide an essential 221 step to advance understanding of external forcing on natural climate variability during the past 2,500 222 years. With the expected detection of additional rapid $\Delta^{14} \mathrm{C}$ enrichment events from ongoing efforts 223 in annual resolution ${ }^{14} \mathrm{C}$ tree-ring analyses ${ }^{49}$, there will be future opportunities to further constrain 224 ice-core dating throughout the Holocene and develop a framework of precisely dated, globally 225 synchronized proxies of past climate variability and external climate forcing.

2261 Robock, A. Volcanic eruptions and climate. Rev Geophys 45, doi: 1029/2007rg000232 (2007).

2272 Hanhijarvi, S., Tingley, M. P. \& Korhola, A. Pairwise comparisons to reconstruct mean 228 temperature in the Arctic Atlantic Region over the last 2,000 years. Clim Dynam 41, 20392292060 (2013).

2303 PAGES 2k Consortium Continental-scale temperature variability during the past two 231 millennia. Nature Geoscience 6, doi: 10.1038/Ngeo1834 (2013).

2324 Mann, M. E. et al. Proxy-based reconstructions of hemispheric and global surface temperature variations over the past two millennia. P Natl Acad Sci USA 105, 13252-13257, (2008). 
2355 Usoskin, I. G. A history of solar activity over millenia. Living Rev Sol. Phys 10,

236 doi:10.12942/Irsp-2013-1 (2013).

2376 Gao, C. C., Robock, A. \& Ammann, C. Volcanic forcing of climate over the past 1500 years: An

238 improved ice core-based index for climate models. J Geophys Res-Atmos 113, doi: D23111

$239 \quad 10.1029 / 2008 j d 010239$ (2008).

2407 Crowley, T. J. \& Unterman, M. B. Technical details concerning development of a 1200-yr

241 proxy index of global volcanism. Earth System Science Data 5, 187-197 (2013).

2428 Mann, M. E., Fuentes, J. D. \& Rutherford, S. Underestimation of volcanic cooling in tree-ring-

243 based reconstructions of hemispheric temperatures. Nat Geosci 5, 202-205 (2012).

2449 Mann, M. E., Rutherford, S., Schurer, A., Tett, S. F. B. \& Fuentes, J. D. Discrepancies between

245 the modeled and proxy-reconstructed response to volcanic forcing over the past millennium:

246 Implications and possible mechanisms. J Geophys Res-Atmos 118, 7617-7627 (2013).

24710 Schurer, A. P., Hegerl, G. C., Mann, M. E., Tett, S. F. B. \& Phipps, S. J. Separating Forced from

248 Chaotic Climate Variability over the Past Millennium. J Climate 26, 6954-6973 (2013).

24911 Anchukaitis, K. J. et al. Tree rings and volcanic cooling. Nat Geosci 5, 836-837 (2012).

25012 Büntgen, U. et al. Extraterrestrial confirmation of tree-ring dating. Nat Clim Change 4, 404-

$251405(2014)$.

25213 Esper, J., Büntgen, U., Luterbacher, J. \& Krusic, P. J. Testing the hypothesis of post-volcanic 253 missing rings in temperature sensitive dendrochronological data. Dendrochronologia 31, 254 216-222 (2013).

25514 D'Arrigo, R., Wilson, R. \& Anchukaitis, K. J. Volcanic cooling signal in tree ring temperature 256 records for the past millennium. J Geophys Res-Atmos 118, 9000-9010 (2013).

25715 Plummer, C. T. et al. An independently dated 2000-yr volcanic record from Law Dome, East 258 Antarctica, including a new perspective on the dating of the 1450s CE eruption of Kuwae, 259 Vanuatu. Clim Past 8, 1929-1940 (2012). 
26016 Sigl, M. et al. A new bipolar ice core record of volcanism from WAIS Divide and NEEM and

261 implications for climate forcing of the last 2000 years. J Geophys Res-Atmos 118, 1151-1169

262 (2013).

26317 Sigl, M. et al. Insights from Antarctica on volcanic forcing during the Common Era. Nat Clim

$264 \quad$ Change 4, 693-697 (2014).

26518 Esper, J. et al. European summer temperature response to annually dated volcanic eruptions

266 over the past nine centuries. B Volcanol 75, doi: 10.1007/S00445-013-0736-Z (2013).

26719 Douglass, D. H. \& Knox, R. S. Climate forcing by the volcanic eruption of Mount Pinatubo.

268 Geophys Res Lett 32, L05710, doi: 10.1029/2004gl022119 (2005).

26920 Baillie, M. G. L. Proposed re-dating of the European ice core chronology by seven years prior

270 to the 7th century AD. Geophys Res Lett 35, L15813, doi: 10.1029/2008gl034755 (2008).

$27121 \quad$ Baillie, M. G. L. \& McAneney, J. Tree ring effects and ice core acidities clarify the volcanic

272 record of the 1st millennium. Clim. Past 11, 105-114 (2015).

27322 Miyake, F., Nagaya, K., Masuda, K. \& Nakamura, T. A signature of cosmic-ray increase in AD

274 774-775 from tree rings in Japan. Nature 486, 240-242 (2012).

27523 Miyake, F., Masuda, K. \& Nakamura, T. Another rapid event in the carbon-14 content of tree

$276 \quad$ rings. Nat Commun 4, doi: 10.1038/Ncomms2783 (2013).

27724 Usoskin, I. G. et al. The AD775 cosmic event revisited: the Sun is to blame. Astron Astrophys $278 \quad$ 552, doi: 10.1051/0004-6361/201321080 (2013).

27925 Jull, A. J. T. et al. Excursions in the 14C record at A. D. 774-775 in tree rings from Russia and $280 \quad$ America. Geophys Res Lett 41, 3004-3010 (2014).

28126 Güttler, D. et al. Rapid increase in cosmogenic 14C in AD 775 measured in New Zealand kauri 282 trees indicates short-lived increase in 14C production spanning both hemispheres. Earth

283 Planet. Sci. Lett. 411, 290-297 (2015).

28427 Miyake, F. et al. Cosmic ray event of AD 774-775 shown in quasi-annual 10 Be data from the 285 Antarctic Dome Fuji ice core. Geophys. Res. Lett. 42, 84-89 (2015). 
28628 Webber, W. R., Higbie, P. R. \& McCracken, K. G. Production of the cosmogenic isotopes H-3,

$287 \mathrm{Be}-7, \mathrm{Be}-10$, and $\mathrm{Cl}-36$ in the Earth's atmosphere by solar and galactic cosmic rays. J Geophys

288 Res-Space 112, A10106, doi: 10.1029/2007ja012499 (2007).

28929 Masarik, J. \& Beer, J. An updated simulation of particle fluxes and cosmogenic nuclide

290 production in the Earth's atmosphere. J Geophys Res-Atmos 114, D11103, doi:

$291 \quad 10.1029 / 2008 j d 010557$ (2009).

$29230 \quad$ Vinther, B. M. et al. A synchronized dating of three Greenland ice cores throughout the

293 Holocene. J Geophys Res-Atmos 111, D13102, doi: 10.1029/2005jd006921 (2006).

29431 Lavigne, F. et al. Source of the great A.D. 1257 mystery eruption unveiled, Samalas volcano,

295 Rinjani Volcanic Complex, Indonesia. P Natl Acad Sci USA 110, 16742-16747 (2013).

29632 Winstrup, M. et al. An automated approach for annual layer counting in ice cores. Clim Past

$297 \quad 8,1881-1895(2012)$.

29833 McCormick, M. et al. Climate Change during and after the Roman Empire: Reconstructing

299 the Past from Scientific and Historical Evidence. J Interdiscipl Hist 43, 169-220 (2012).

30034 Salzer, M. W. \& Hughes, M. K. Bristlecone pine tree rings and volcanic eruptions over the last

3015000 yr. Quaternary Res 67, 57-68 (2007).

30235 Esper, J., Duthorn, E., Krusic, P. J., Timonen, M. \& Buntgen, U. Northern European summer

303 temperature variations over the Common Era from integrated tree-ring density records. J

304 Quaternary Sci 29, 487-494 (2014).

30536 Crowley, T. J. Causes of climate change over the past 1000 years. Science 289, 270-277

306 (2000).

30737 Driscoll, S., Bozzo, A., Gray, L. J., Robock, A. \& Stenchikov, G. Coupled Model

308 Intercomparison Project 5 (CMIP5) simulations of climate following volcanic eruptions. J

309 Geophys Res-Atmos 117, D17105, doi: 10.1029/2012jd017607 (2012). 
31038 Schneider, D. P., Ammann, C. M., Otto-Bliesner, B. L. \& Kaufman, D. S. Climate response to

311 large, high-latitude and low-latitude volcanic eruptions in the Community Climate System

312 Model. J Geophys Res-Atmos 114, D15101, doi: 10.1029/2008jd011222 (2009).

31339 Zanchettin, D. et al. Inter-hemispheric asymmetry in the sea-ice response to volcanic forcing

314 simulated by MPI-ESM (COSMOS-Mill). Earth Syst Dynam 5, 223-242 (2014).

31540 Stothers, R. B. Mystery Cloud of Ad-536. Nature 307, 344-345 (1984).

31641 Larsen, L. B. et al. New ice core evidence for a volcanic cause of the AD 536 dust veil.

317 Geophys Res Lett 35, L04708, doi: 10.1029/2007gl032450 (2008).

31842 Büntgen, U. et al. 2500 Years of European Climate Variability and Human Susceptibility.

$319 \quad$ Science 331, 578-582 (2011).

32043 Esper, J. et al. Orbital forcing of tree-ring data. Nat Clim Change 2, 862-866 (2012).

32144 D'Arrigo, R. et al. 1738 years of Mongolian temperature variability inferred from a tree-ring

322 width chronology of Siberian pine. Geophys Res Lett 28, 543-546 (2001).

32345 Zhang, Z. B. et al. Periodic climate cooling enhanced natural disasters and wars in China

324 during AD 10-1900. P Roy Soc B-Biol Sci 277, 3745-3753 (2010).

32546 Stothers, R. B. Volcanic dry fogs, climate cooling, and plague pandemics in Europe and the

$326 \quad$ Middle East. Climatic Change 42, 713-723 (1999).

32747 Stenseth, N. C. et al. Plague dynamics are driven by climate variation. P Natl Acad Sci USA

$328 \quad 103,13110-13115(2006)$.

32948 Dull, R. A. Evidence for forest clearance, agriculture, and human-induced erosion in

330 Precolumbian El Salvador. Ann Assoc Am Geogr 97, 127-141 (2007).

33149 Taylor, R. E. \& Southon, J. Reviewing the Mid-First Millennium BC C-14 "warp" using C-

332 14/bristlecone pine data. Nucl Instrum Meth B 294, 440-443 (2013).

333

334 Supplementary Information is available in the online version of the paper. 
335 Acknowledgements. We thank the many persons involved in logistics, drill development and drilling, 336 and ice-core processing and analysis in the field and our laboratories. This work was supported by 337 the U.S. National Science Foundation (NSF). The authors appreciate support of the WAIS Divide 338 Science Coordination Office (M. Twickler and J. Souney) for collection and distribution of the WAIS 339 Divide ice core; Ice Drilling and Design and Operations (K. Dahnert) for drilling; the National Ice Core 340 Laboratory (B. Bencivengo) for curating the core; Raytheon Polar Services (M. Kippenhan) for 341 logistics support in Antarctica; and the $109^{\text {th }}$ New York Air National Guard for airlift in Antarctica. 342 NEEM is directed and organized by the Center of Ice and Climate at the Niels Bohr Institute and U.S. 343 NSF, Office of Polar Programs. It is supported by funding agencies and institutions in Belgium (FNRS344 CFB and FWO), Canada (NRCan/GSC), China (CAS), Denmark (FIST), France (IPEV, CNRS/INSU, CEA 345 and ANR), Germany (AWI), Iceland (Rannls), Japan (NIPR), Korea (KOPRI), The Netherlands 346 (NWO/ALW), Sweden (VR), Switzerland (SNF), United Kingdom (NERC), and the USA (U.S. NSF, Office 347 of Polar Programs). We thank B. Nolan, O. Amir, K. D. Pang, M. McCormick, A. Matthews, and B. 348 Rossignol for assistance in surveying and/or interpreting the historical evidence. We thank S. Kuehn 349 for commenting on possible correlations for the tephra. A. Aldahan and G. Possnert are thanked for 350 their support in the NGRIP ${ }^{10} \mathrm{Be}$ preparations and measurements at the Department of Earth 351 Sciences and the Tandem laboratory at Uppsala University. We gratefully acknowledge R. Kreidberg 352 for his editorial advice.

The following individual grants supported this work: NSF/OPP grants 0839093, 0968391, and 1142166 to J.R.M. for development of the Antarctic ice core records and NSF/OPP grants 0909541, 1023672, and 1204176 to J.R.M. for development of the Arctic ice core records. M.W. was funded by the Villum Foundation. K.C.W. was funded by NSF/OPP grants 0636964 and 0839137 . M.W.C. and T.W. were funded by NSF/OPP grants 0839042 and 0636815 . F.L. was funded by the Yale Climate \& Energy Institute, Initiative for the Science of the Human Past at Harvard, and Rachel Carson Center for Environment and Society of the Ludwig-Maximilians-Universität (LMU Munich). C.K. was funded 
Sa. was funded by NSF grant ATM 1203749. R.M. was funded by the Swedish Research Council 362 (DNR2013-8421). The division of Climate and Environmental Physics, Physics Institute, University of Bern, acknowledges financial support by the SNF and the Oeschger Centre.

Author Contributions. M.Si. designed the study with input from J.R.M., M.W., G.P., and F.L. The manuscript was written by M.Si., M.W., F.L., and J.R.M., with contributions from K.C.W., G.P., U.B., B.V. in interpretation of the measurements. Ice-core chemistry measurements were performed by J.R.M., M.Si., O.J.M., N.C., D.R.P. (NEEM, B40, TUNU2013), and by S.S., H.F., R.Mul. (NEEM). K.C.W., manuscript.

Author Information. The authors declare no competing financial interests. Correspondence and requests for materials should be addressed to J.R.M. (Joe.McConnell@dri.edu).

Figure 1 | Annual ${ }^{10} \mathrm{Be}$ ice-core records and post-volcanic cooling from tree rings under existing icecore chronologies. a) Superposed epoch analysis for the seven largest volcanic signals in NEEM2011-S1 between 78 and 1000 CE and for the 10 largest eruptions between 1250 and 2000 CE, respectively ${ }^{16}$. Shown are growth anomalies from a multi-centennial, temperature-sensitive tree-ring composite ( $\mathrm{N}-$ Tree $\mathrm{T}^{42,43,76-78}$, Methods) 10 years after the year of volcanic sulfate deposition at NEEM ice core site in Greenland (GICC05 timescale), relative to the level five years prior to sulfate deposition; b) annually resolved ${ }^{10}$ Be concentration records from WDC, TUNU2013, NGRIP, and 
NEEM-2011-S1 ice cores on their original timescales and annually resolved $\Delta^{14} \mathrm{C}$ series from tree-ring records between $755-795 \mathrm{CE}^{22,24}$, with arrows representing the suggested time shifts for synchronization; error bars are $1 \sigma$ measurement uncertainties; estimated relative age uncertainty for TUNU2013 at this depth interval from volcanic synchronization with NEEM-2011-S1 is \pm 1 year; c) annually resolved ${ }^{10}$ Be concentration record from NEEM-2011-S1 ice core on its original timescale and annually resolved $\Delta^{14} \mathrm{C}$ series from tree rings between $980-1010 \mathrm{CE}^{23}$; error bars are $1 \sigma$ measurement uncertainties.

\section{Figure 2 | Re-dated ice-core, non-sea-salt sulfur records from Greenland and Antarctica in relation} to growth anomalies in the N-Tree composite. a) Upper panel: Ice-core, non-sea-salt sulfur (nssS) records from Greenland (NEEM, NEEM-2011-S1) on the NS1-2011 timescale between 500 BCE and $1300 \mathrm{CE}$, with identified layer of Tianchi tephra ${ }^{67}$ highlighted (orange star). Calendar years are given for the start of volcanic sulfate deposition. Events used as fixed age markers to constrain the dating (i.e., 536, 626, 775, 939, and 1258) are indicated (purple stars). Annually resolved ${ }^{10} \mathrm{Be}$ concentration record (green) from NEEM-2011-S1 encompassing the two $\Delta^{14} C$ excursion events in trees from 775 and 994; middle panel: tree-ring growth anomalies (relative to 1000-1099 CE) for the N-Tree composite $^{42,43,76-78}$; lower panel: nssS records from Antarctica (WDC, B40) on the WD2014 timescale and annually resolved ${ }^{10} \mathrm{Be}$ concentrations from WDC; $\mathbf{b}$ ) superposed epoch analysis for 28 large volcanic signals during the past 2,500 years. Tree-ring growth anomalies relative to the timing of reconstructed sulfate deposition in Greenland (NS1-2011) are shown for 1250 to 2000 CE and 500 BCE to $1250 \mathrm{CE}$.

Figure 3 | Global volcanic aerosol forcing and NH temperature variations for the past 2,500 years. a) 2,500 year record of tree-growth anomalies ( $\mathrm{N}$-Tree ${ }^{42,43,76-78}$; relative to $1000-1099 \mathrm{CE}$ ) and reconstructed summer temperature anomalies for Europe and $\mathrm{Arctic}^{3} ; 40$ coldest single years and 12 coldest decades based on $\mathrm{N}$-Tree are indicated; $\mathbf{b}$ ) reconstructed global volcanic aerosol forcing from bipolar sulfate composite records from tropical (bipolar), $\mathrm{NH}$, and $\mathrm{SH}$ eruptions. Total (i.e., time 
integrated) forcing values are calculated by summing the annual values for the duration of volcanic

sulfur deposition. 40 largest volcanic signals are indicated, and ages are given for events representing atmospheric sulfate loading exceeding Tambora 1815.

Figure 4 | Post-volcanic cooling. Superposed composites (time segments from selected periods in the Common Era positioned so that the years with peak negative forcing are aligned) of the JJA temperature response to: a)-c) 24 largest eruptions (>Pinatubo 1991) for three regional eruptions with negative forcing larger than Tambora 1815 for Northern Europe and i) for Central Europe (note the different scale for g-i); shown are JJA temperature anomalies $\left({ }^{\circ} \mathrm{C}\right.$ ) for 15 years after reconstructed volcanic peak forcing, relative to the five years before the volcanic eruption. Dashed lines present two times the standard error of the mean (2 SEM) of the temperature anomalies associated with the multiple eruptions. 5-year average post-volcanic temperatures are shown for each reconstruction (lag 0 to lag +4 yrs, gray shading).

Figure 5 | Volcanism and temperature variability during the Migration Period (500-705 CE). Upper

panel: Ice-core non-sea-salt sulfur (nssS) records from Greenland (NEEM-2011-S1, TUNU2013). effects in 536-537 and 626-627 CE. Calendar years for five large eruptions are given for the start of volcanic sulfate deposition; middle panel: Summer temperature anomalies for Europe ${ }^{3}$, and reconstructed $\mathrm{N}$-Tree growth anomalies and occurrence of frost rings in North American bristlecone pine tree-ring records; lower panel: nssS records from Antarctica (WDC, B40) on the WD2014

431 timescale; attribution of the sulfur signals to bipolar, $\mathrm{NH}$, and $\mathrm{SH}$ events based on the timing of

432 deposition on the two independent timescales is indicated by shading.

Methods

434 Ice cores. This study included new and previously described ice-core records from five drilling sites

435 (Extended Data Fig. 1, Supplementary Data S1). The upper $577 \mathrm{~m}$ of the 3,405 m WAIS Divide (WDC) 
core from central West Antarctica and a 410 m intermediate-length core (NEEM-2011-S1) drilled in 2011 close to the 2,540 m North Greenland Eemian Ice Drilling (NEEM) ${ }^{50}$ ice core previously have been used to reconstruct sulfate deposition in both polar ice sheets ${ }^{16}$. These coring sites are characterized by relatively high snowfall ( $\left.200 \mathrm{~kg} \mathrm{~m}^{-2} \mathrm{yr}^{-1}\right)$ and have comparable elevation, latitude, and deposition regimes. WDC and NEEM-2011-S1 provided high-resolution records that allowed annual-layer dating based on seasonally varying impurity content ${ }^{16}$. New ice-core analyses included the upper $514 \mathrm{~m}$ of the main NEEM core used to extend the record of NEEM-2011-S1 to cover the past 2,500 years, as well as B40 drilled in 2012 in Dronning Maud Land in East Antarctica and TUNU2013 drilled in 2013 in Northeast Greenland - both characterized by lower snowfall rates ( 70$\left.100 \mathrm{~kg} \mathrm{~m}^{-2} \mathrm{yr}^{-1}\right)$. Volcanic sulfate concentration from B40 had been reported previously for the past 2,000 years $^{17}$, but we extended measurements to $200 \mathrm{~m}$ depth to cover the past 2,500 years.

High-resolution, ice-core aerosol analyses. Ice-core analyses were performed at the Desert Research Institute (DRI) using 55 to $100 \mathrm{~cm}$ long, longitudinal ice core sections ( $33 \times 33 \mathrm{~mm}$ wide). The analytical system for continuous analysis included two Element2 (Thermo Scientific) highresolution inductively coupled plasma mass spectrometers (HR-ICP-MS) operating in parallel for measurement of a broad range of 35 elements; an SP2 (Droplet Measurement Technologies) instrument for black carbon (BC) measurements; and a host of fluorimeters and spectrophotometers for ammonium $\left(\mathrm{NH}_{4}{ }^{+}\right)$, nitrate $\left(\mathrm{NO}_{3}{ }^{-}\right)$, hydrogen peroxide $\left(\mathrm{H}_{2} \mathrm{O}_{2}\right)$, and other chemical species. All measurements were exactly co-registered in depth, with depth resolution typically less than 10-15 $\mathrm{mm}^{51-53}$. We corrected total sulfur $(\mathrm{S})$ concentrations for the sea-salt-sulfur contribution using seasalt-Na concentrations ${ }^{16}$. Measurements included TUNU2013 and NEEM (400-515 m) in Greenland, and B40 in Antarctica (Extended Data Fig. 1). Gaps (i.e., ice not allocated to DRI) in the highresolution sulfur data of the NEEM core were filled with $\sim 4 \mathrm{~cm}$ resolution discrete sulfate measurements using fast ion-chromatography techniques ${ }^{54}$ performed in the field between 428 and $506 \mathrm{~m}$ depth. 
using a continuous flow analysis (CFA) system ${ }^{55}$ recently modified to include a new melter head

absorption spectroscopy; conductivity of the meltwater by a micro flow cell (Amber Science Inc.);

and a particle detector (Abakus, Klotz) was used for measuring insoluble dust particle concentrations and size distribution ${ }^{57}$. Effective depth resolution typically was better than $20 \mathrm{~mm}$. Measurements were exactly synchronized in depth using a multicomponent standard solution; the accuracy of the depth assignment for all measurements typically was better than $5 \mathrm{~mm}$.

High-resolution measurements of ${ }^{10} \mathrm{Be}$ in ice cores using accelerator mass spectrometry (AMS). Samples from the NEEM-2011-S1, WDC, NGRIP, and TUNU2013 ice cores encompassing the time period of the $\Delta^{14} \mathrm{C}$ anomalies from tree-ring records ${ }^{12,22-25}$ were used for ${ }^{10} \mathrm{Be}$ analysis (Supplementary Data S1). NEEM-2011-S1 and WDC were sampled in exact annual resolution, using the maxima (minima in WDC) of the annual cycles of $\mathrm{Na}$ concentrations to define the beginning of the calendar year ${ }^{16}$. NGRIP was sampled at a constant resolution of $18.3 \mathrm{~cm}$ providing an age resolution of about one year. Similarly, TUNU2013 was sampled in quasi-annual resolution according to the average annual-layer thickness expected at this depth based on prior volcanic synchronization to NEEM-2011-S1. The relative age uncertainty for TUNU2013 with respect to the dependent NEEM2011-S1 chronology at this depth is assumed to be \pm 1 year at most given a distinctive match for selected volcanic trace elements in both ice core records (752-764 CE, NS1-2011 timescale). Sample masses ranged between 100 and $450 \mathrm{~g}$, resulting in median overall quantification uncertainties of

481 less than $4-7 \%$. The ${ }^{10} \mathrm{Be} /{ }^{9} \mathrm{Be}$ ratios of samples and blanks were measured relative to welldocumented ${ }^{10}$ Be standards ${ }^{13}$ by AMS at Purdue's PRIME laboratory (WDC, NEEM-2011-S1, Tunu2013) and Uppsala University (NGRIP) ${ }^{58,59}$. Results were corrected for an average blank ${ }^{10} \mathrm{Be} /{ }^{9} \mathrm{Be}$ ratio, corresponding to corrections of $2-10 \%$ of the measured ${ }^{10} \mathrm{Be} /{ }^{9} \mathrm{Be}$ ratios. 
$m)$, and NEEM (410-515 m), as well as NEEM aerosol concentration data (183-514 m) from the fieldbased CFA system. The original timescale for NEEM-2011-S1 was based on volcanic synchronization to the NGRIP sulfate record on the GICCO5 timescale and annual-layer interpretation between the volcanic age markers, while WDC previously was dated by annual-layer counting ${ }^{16}$.

Parameters with strong intra-annual variability included tracers of sea salt (e.g., $\mathrm{Na}, \mathrm{Cl}, \mathrm{Sr}$ ), dust (e.g., $\mathrm{Ce}, \mathrm{Mg}$, insoluble particle concentration), and marine biogenic emissions such as non-seasalt sulfur (nssS). Tracers of biomass-burning emissions, such as $\mathrm{BC}, \mathrm{NH}_{4}{ }^{+}$, and $\mathrm{NO}_{3}{ }^{-}$, also showed strong seasonal variations in deposition during pre-industrial times ${ }^{16,60,61}$. Datasets used for annual layer interpretation are provided in Extended Data Table 1. For NEEM-2011-S1, the final database used for annual-layer dating included 13 parameters and the ratio of nssS/Na. For WDC, the final database included five parameters and the ratio of nssS/Na. For NEEM (410-515 m depth), the final database included eight parameters $\left(\mathrm{Na}^{+}, \mathrm{Ca}^{2+}, \mathrm{NH}_{4}^{+}, \mathrm{H}_{2} \mathrm{O}_{2}, \mathrm{NO}_{3}^{-}\right.$, conductivity, insoluble particle concentrations, and $\left.\mathrm{ECM}^{62}\right)$ from the field-based measurements and eleven parameters $(\mathrm{Na}, \mathrm{Cl}, \mathrm{Mg}$, $\mathrm{Mn}, \mathrm{Sr}, \mathrm{nssS}, \mathrm{nssS} / \mathrm{Na}$, nssCa, $\mathrm{BC}, \mathrm{NO}_{3}{ }^{-}, \mathrm{NH}_{4}{ }^{+}$) from the DRI system.

We focused here on the time period prior to the large volcanic eruption of Samalas in 1257 $\mathrm{CE}^{31}$, clearly detectable as an acidic peak in both ice-core records, and consequently started annuallayer counting of NEEM-2011-S1, NEEM, and WDC at the depth of the corresponding sulfur signal. For the time period 1257 CE to present, ice-core chronologies were constrained by numerous historic eruptions and large sulfate peaks showing a strong association to Northern Hemisphere (NH) cooling events as indicated by tree-ring records ${ }^{16}$.

We applied the StratiCounter layer-detection algorithm ${ }^{32}$ to the multi-parameter aerosol concentration records ( $n=14$ for NEEM-2011-S1; $n=6$ for WDC; $n=8$ for NEEM $<410$ m; $n=19$ for NEEM $>410 \mathrm{~m}$ ) to objectively determine the most likely number of annual layers in the ice cores along with corresponding uncertainties. The StratiCounter algorithm is based on statistical inference in Hidden Markov Models (HMMs), and it determines the maximum likelihood solution based on the annual 
signal in all aerosol records in parallel. Some of these displayed a high degree of similarity, so we weighted these records correspondingly lower. The algorithm was run step-wise down the core, each batch covering approximately 50 years, with a slight overlap. All parameters for the statistical description of a mean layer and its inter-annual variability in the various aerosol records were determined independently for each batch as the maximum likelihood solution. The algorithm simultaneously computes confidence intervals for the number of layers within given sections, allowing us to provide uncertainty bounds on the number of layers between selected age-marker horizons (Extended Data Table 2). frequent occurrence of small gaps in the two independent high-resolution aerosol data sets. provided an almost complete aerosol record with $96 \%$ data coverage. As this was the first time that the StratiCounter algorithm was used simultaneously on data records from two different melt systems, with different characteristics and lack of exact co-registration, we also manually determined annual layers below $410 \mathrm{~m}$ using the following approaches: one investigator used $\mathrm{Na}$ and nssCa concentrations and the ratio of nssS/ $\mathrm{Na}$ (from DRI analysis) as well as $\mathrm{Na}^{+}$and insoluble particle concentrations (from CFA analysis) as primary dating parameters. $\mathrm{BC}, \mathrm{NH}_{4}{ }^{+}$, nssS, and conductivity were used as secondary dating parameters where annual-layer interpretation was ambiguous. A second investigator used DRI's $\mathrm{Na}, \mathrm{Ca}, \mathrm{BC}, \mathrm{NH}_{4}{ }^{+}$and $\mathrm{CFA} \mathrm{Na}{ }^{+}, \mathrm{Ca}^{2+}$, and $\mathrm{NH}_{4}{ }^{+}$ measurements as parameters. The annual-layer interpretation of the NEEM core between 410 and $514 \mathrm{~m}$ from investigator 1 was within the interpretation uncertainties of the StratiCounter output, 534 from which it differed less than a single year over the majority of this section, and it differed from 535 independently counted timescales (e.g., GICC05) ${ }^{62}$ by on average less than three years (Extended Data Fig. 2). This set of layer counts was used for the resulting timescale. 
537 New ice-core chronologies (NS1-2011, WD2014). We defined the depth of NEEM-2011-S1

538 containing the maximum ${ }^{10} \mathrm{Be}$ concentration as the year $775 \mathrm{CE}$. Relative to this constraint, the

539 maximum likelihood ages for three large volcanic sulfate peaks were within \pm 1 year of documented

540 historical reports from early written sources of prominent and sustained atmospheric dimming

541 observed in Europe and/or the Near East (Extended Data Table 3, Supplementary Data S2).

542 Automated-layer identification for NEEM-2011-S1 was therefore constrained by tying the respective

543 ice-core volcanic signals to the corresponding absolute historically-dated ages of 536, 626, and 939

544 CE (Extended Data Table 2) - thereby creating a new ice-core timescale (NS1-2011). The volcanic

545 sulfur signal corresponding to the eruption of Samalas believed to have occurred in late $1257^{31}$ was

546 constrained to 1258 CE to account for several months' delay in sulfate deposition in the high

547 latitudes. Before 86 CE (the bottom depth of NEEM-2011-S1), the NS1-2011 timescale was extended

548 using the manually-derived annual-layer interpretation of the combined NEEM aerosol data-sets

549 back to 500 BCE (Fig. 2).

550 In NS1-2011 we did not attribute acid layers to the historical eruptions Vesuvius 79 and

551 Hekla 1104, due to a lack of corroborative tephra at these depths in this and a previous study ${ }^{63}$.

552 Possible Vesuvian tephra was reported from the Greenland Ice Sheet Project (GRIP) ice core at 429.3

$553 \mathrm{~m} \mathrm{depth}^{64}$, but in view of the new annual-layer dating results (Extended Data Fig. 3), we concluded

554 that this layer dates to $87 / 88$ CE. Furthermore, volcanic sulfate deposition values for the

555 corresponding event show a strong spatial gradient over Greenland with highest values in NW

556 Greenland $^{16}$ and lowest in Central and South Greenland ${ }^{65}$, favoring the attribution of a volcanic

557 source from the high latitudes. Documentary sources (Supplementary Data S2) also suggest that the

558 main vector of ash transport following the Vesuvius 79 CE eruption was toward the eastern

559 Mediterranean ${ }^{66}$.

560 For WDC, we do not have other sufficiently well-determined age constraints besides the

561 rapid ${ }^{10} \mathrm{Be}$ increase in $775 \mathrm{CE}$ and the sulfur signal of the Samalas 1257 eruption. Therefore, no 
additional constraints were used when creating the new ice-core timescale ("WD2014") from the StratiCounter annual-layer interpretation back to 396 BCE.

Depth-age information for six distinctive marker horizons in Greenland is given, and five of these horizons were used to constrain NS1-2011 (Extended Data Table 3). Similarly, depth information, the number of annual layers, and $95 \%$ confidence intervals between distinctive volcanic marker horizons are given for NEEM, NEEM-2011-S1, and WDC, supporting attribution of these icecore signals to eruptions in the low latitudes with bipolar sulfate deposition.

Evaluation of NS1-2011 using independent age information. We evaluated timescale accuracy using additional distinctive age markers not used during chronology development:

1) Tephra from the eruption of Changbaishan/Tianchi (China) ${ }^{67}$ was detected in NEEM-2011-S1 in 946-947 CE, in agreement with widespread documentary evidence of an eruption in that region in winter $946 / 47 \mathrm{CE}^{68}$ also supported by a high-precision ${ }^{14} \mathrm{C}$ wiggle-match age of $946 \pm$ 3 CE obtained from a tree killed during this eruption ${ }^{68}$.

2) The rapid increase of ${ }^{10} \mathrm{Be}$ from the 994 event occurred in NEEM-2011-S1 in $993 \mathrm{CE}$, consistent with $\Delta^{14} \mathrm{C}$ from Japanese tree rings showing that the rapid increase in radionuclide production took place between the $\mathrm{NH}$ growing seasons of 993 and $994 \mathrm{CE}^{23}$.

3) To assess the accuracy of the NS1-2011 timescale prior to the earliest age marker at 536 CE, we compiled an independent time series of validation points, featuring years with well dated historical reports of atmospheric phenomena associated with high-altitude volcanic dust and/or aerosols (Supplementary Data S2) as known from modern observations to occur after major eruptions (e.g., Krakatau, 1883). These phenomena include diminished sunlight, discoloration of the solar disk, solar coronae (i.e., Bishop's Rings), and deeply red twilights (i.e., volcanic sunsets) ${ }^{69,70}$. Thirty-two events met our criteria as validation points for the pre536 CE NS1-2011 timescale. For the earliest in 255 BCE, it was reported in Babylon that "the disk of the sun looked like that of the moon"73. For the latest in $501 \mathrm{CE}$, it was reported in 
North China that "the Sun was red and without brilliance" ${ }^{\text {"74 }}$. We found that NEEM volcanic event years (including both NEEM and NEEM-2011-S1 data) occurred closely in time (i.e., within a conservative \pm 3 year margin) to 24 (75.0\%) of our validation points (Extended Data Figure 2). To assess whether this association arose solely by chance, we conducted a Monte

Potential causes of a previous ice-core dating bias. Interpretation of annual layers in ice cores is subject to accumulating age uncertainty due to ambiguities in the underlying ice-core profiles ${ }^{30,73}$. measured at $5 \mathrm{~cm}$ depth resolution ${ }^{15}$ similarly was synchronized to NS1-2011 using 124 volcanic tieCarlo equal means test with 1,000,000 iterations (Supplementary Data S2) and found that the number of volcanic event years within \pm 3 years of our validation points was significantly greater than expected randomly $(p<0.001)$. A significant association was also observed $(p<0.001)$ when using less conservative error margins ( \pm 1 and \pm 2 years) and when excluding any historical observations with less certainty of a volcanic origin (Supplementary Data S2). When placing volcanic event years on the original GICC05 timescale, we did not observe any statistically significant association with our independent validation points.

Bias in existing chronologies may arise from several factors, including: 1) low effective resolution of some ice core measurements (NGRIP, GRIP); 2) use of only single (or few) parameters for annuallayer interpretation (GRIP, Dye-3); 3) intra-annual variations in various ice-core parameters falsely interpreted as layer boundaries (e.g., caused by summer melt in Dye-3) $)^{74}$; 4 ) use of tephra believed to originate from the 79 CE Vesuvian eruption ${ }^{64}$ as a fixed reference horizon to constrain the Greenland ice-core dating $^{30}$; 5) use of manual-layer interpretation techniques that may favor interpretations consistent with a priori knowledge or existing chronologies (WDC) ${ }^{16,21}$.

\section{Volcanic synchronization of B40, TUNU2013, and NGRIP to WDC and NEEM. Two high-resolution} sulfur ice-core records (TUNU2013, Greenland and B40, Antarctica) were synchronized to NEEM2011-S1 and WDC, respectively, using volcanic stratigraphic age markers ${ }^{17}$ with relative age uncertainty between the tie-points estimated to not exceed \pm 2 years. The NGRIP sulfate record points between 226 and 1999 CE. During the time period with no sulfur record yet available for WDC 
613 (before $396 \mathrm{BCE}$ ), a tentative chronology for B40 was derived by linearly extrapolating mean annual-

614 layer thickness for B40 as derived from the synchronization to WDC between the earliest volcanic

615 match points.

6162,500 year global volcanic forcing ice-core index. We constructed an index of global volcanic aerosol

617 forcing by (1) re-dating and extending to $500 \mathrm{BCE}$ an existing reconstruction of sulfate flux from an

618 Antarctic ice-core array ${ }^{17}$ by applying an area weighting of $80 / 20$ between East Antarctica and West

619 Antarctica to B40 and WDC volcanic sulfate flux values, respectively; (2) compositing NGRIP and the

620 NEEM-2011-S1/NEEM sulfate flux records to a similar Greenland sulfate deposition composite back

621 to 500 BCE; (3) using established scaling functions $s^{6,75}$ to estimate hemispheric sulfate aerosol loading

622 from both polar ice-core composites; and (4) scaling global aerosol loading to the total (i.e., time

623 integrated) radiative volcanic aerosol forcing following the Tambora 1815 eruption ${ }^{7}$. Since the NS1-

6242011 and WD2014 timescales are independent of each other, the timing of bipolar events had to be

625 adjusted to follow a single timescale to derive a unified global volcanic forcing series. We chose NS1-

6262011 as the reference chronology for most of the volcanic time series because this age model was

627 constrained and validated by more stratigraphic age markers than WD2014. WD2014 was used as

628 the reference chronology only between 150 and $450 \mathrm{CE}$, because of better data quality during that

629 time period. TUNU2013 was not included in the Greenland ice-core composite because annual-layer

630 thickness variability at this site is influenced strongly by glaciological processes, leading to relatively

631 large uncertainties in atmospheric sulfur-deposition determinations.

632 NH tree-ring composite. Tree-ring records from certain locations reflect summer cooling (as is

633 widespread observed after volcanic eruptions) with no age uncertainty in annual ring-width dating,

634 thus allowing independent validation of ice-core timescales and the derived volcanic forcing indices.

635 However, no tree-ring-based temperature reconstructions of large spatial scales span the full 2,500

636 years represented by our new ice-core chronologies. To thus evaluate our new ice-core chronologies

637 and assess the consistency of response throughout the past 2,500 years, we compiled a composite 
638 (entitled "N-Tree") of multi-centennial tree growth records at locations where temperature is the

639 limiting growth factor. We selected available NH tree-ring records that provided a continuous record

640 of $>1,500$ years and showed a significant positive relationship with JJA temperatures during the

641 instrumental period (1901-2000 CE) with $\mathrm{p}<0.005$ (adjusted for a reduced sample size due to

642 autocorrelation of the datasets). In total, five tree-ring chronologies (three based on ring-width

643 measurements, two based on measurements of maximum latewood density) met these

644 criteria $^{42,43,76-78}$ of which three are located in the high-latitudes of Eurasia (Extended Data Figure 1).

645 As various climatic and non-climatic parameters may influence sensitivity of tree growth to

646 temperatures during the $20^{\text {th }}$ century $^{79-81}$, we used the time period $1000-1099$ CE as a common

647 baseline for standardizing tree growth anomalies among the five chronologies and built a tree

648 growth composite record "N-Tree" (z-scores) by averaging the individual records. Correlations

649 between "N-Tree" ( $N=5)$ and the average of three regional reconstructions for the Arctic, Europe,

650 and Asia $(N>275)^{3}$ between 1800 and 2000 CE are very high $(r=0.86, N=201, p<0.0001)$, suggesting

651 that much of the large-scale variation in temperature is explained by these selected tree-ring

652 records. Three records in "N-Tree" cover the period from 138 BCE to the present, thus allowing at

653 least a qualitative assessment of the coherence of growth reduction following large volcanic

654 eruptions prior to the Common Era (Fig. 2, Extended Data Fig. 4).

655 Temperature reconstructions. To quantify the CE climate impact and investigate regional

656 differences, we used tree-ring-based JJA temperature reconstructions covering the past 2,000 years

657 with demonstrated strong relationship ( $r \geq 0.45 ; p<0.0001$; Extended Data Fig. 1) to instrumental JJA

658 temperature data ${ }^{82}$ between 1901 and 2000. For regions where this criterion was met by several

659 reconstructions (e.g., Scandinavia), we limited the analysis to the most recently updated

660 reconstruction ${ }^{35}$. Three regional reconstructions from Central Europe ${ }^{42}$, Northern Europe ${ }^{35}$, and

661 Northern Siberia (Yamal, not shown) ${ }^{76}$ as well as a continental-scale reconstruction for Europe ${ }^{3}$ met

662 this criterion and were used to quantify the average response of summer temperature to volcanic

663 forcing during the Common Era (Figs. 3, 4). 
664 Superposed epoch analyses. To assess tree-ring growth reduction and summer cooling following

665 large eruptions, we used superposed epoch analyses ${ }^{83,84}$. We selected all volcanic eruptions (28

666 events in total, 24 CE events) with time-integrated volcanic forcing greater than $-7.5 \mathrm{~W} \mathrm{~m}^{-2}$ (i.e.,

667 eruptions larger than Pinatubo 1991) and aligned the individual segments of "N-Tree" and regional

668 JJA temperature reconstructions relative to ice-core-indicated peak forcing. Composite response was

669 calculated for the average of the individual series (lag 0 to lag 10 or 15 years) relative to the average

670 values five years prior to individual volcanic events (lag -5 to lag -1 year). $95 \%$ confidence intervals

671 represent 2 SEM of the tree-growth (Extended Data Figure 4) and temperature anomalies (Figure 4)

672 associated with the multiple eruptions.

673 Cryptotephra analyses of the 536 CE sample from NEEM-2011-S1. We analyzed samples from

674 NEEM-2011-S1 for tephra between 326.73 and $328.06 \mathrm{~m}$ depth, corresponding to 531-539 CE (NS1-

6752011 timescale). Samples (200 to $500 \mathrm{~g}$ ) were filtered, and elemental composition of recovered

676 volcanic glass shards determined by electron microprobe analysis (EPMA) at Queen's University

677 Belfast using established protocols ${ }^{63,67,85}$ and secondary glass standards ${ }^{86,87}$. Between 326.73 and

$678327.25 \mathrm{~m}$, large volume samples were cut at $8 \mathrm{~cm}$ depth resolution $(\leq 0.5 \mathrm{yr})$ and with an average

679 cross section of $26 \mathrm{~cm}^{2}$. Between 327.25 and $328.06 \mathrm{~m}$, the average cross section was $7 \mathrm{~cm}^{2}$ and

680 depth resolution $20 \mathrm{~cm}$ ( $\sim 1 \mathrm{yr}$ resolution). Tephra particles $(\mathrm{n} \geq 17)$ were isolated from a sample of ice

681 (327.17-327.25 $\mathrm{m}$ depth, $251 \mathrm{~g}$ ) corresponding to the sulfate spike at $536 \mathrm{CE}$. The glass shards were

682 heterogeneous in size $(20-80 \mu \mathrm{m})$, morphology (platey, blocky, vesicular, microlitic), and

683 geochemistry (andesitic, trachytic, rhyolitic). Individual shards had geochemical compositions that

684 share affinities with volcanic systems in the Aleutian arc (Alaska) ${ }^{88}$, Northern Cordilleran volcanic

685 province (British Columbia) ${ }^{89}$, and Mono-Inyo Craters area (California) ${ }^{90,91}$ - indicating at least three

686 synchronous eruptive events, all situated in western North America between 38 and $58^{\circ} \mathrm{N}$ (Extended

687 Data Fig. 5; Supplementary Data S5). 
688 Data: Ice-core data (chemistry, including sulfur; ${ }^{10} \mathrm{Be}$ ), resulting timescales, and the volcanic forcing 689 reconstruction are provided as online supplementary material (Supplementary Data S1, S3-S5);

690 Historical documentary data is provided as Supplementary Data S2. The code for the StratiCounter 691 program is accessible at the github repository (http://www.github.com/maiwinstrup/StratiCounter);

692 NGRIP SO 4 data can be obtained at http://www.iceandclimate.nbi.ku.dk/data/2012-12-

03_NGRIP_SO4_5cm_Plummet_et_al_CP_2012.txt ; tree-ring records and temperature

reconstructions are from Pages-2k Consortium (Database S1, S2)

(http://www.nature.com/ngeo/journal/v6/n5/full/ngeo1797.html\#supplementary-information).

\section{References}

69750 Dahl-Jensen, D. et al. Eemian interglacial reconstructed from a Greenland folded ice core.

$698 \quad$ Nature 493, 489-494 (2013).

$69951 \quad$ McConnell, J. R. Continuous ice-core chemical analyses using inductively Coupled Plasma $700 \quad$ Mass Spectrometry. Environ Sci Technol 36, 7-11 (2002).

70152 McConnell, J. R. \& Edwards, R. Coal burning leaves toxic heavy metal legacy in the Arctic. $P$ $702 \quad$ Natl Acad Sci USA 105, 12140-12144 (2008).

70353 Pasteris, D. R. et al. Seasonally resolved ice core records from West Antarctica indicate a sea 704 ice source of sea-salt aerosol and a biomass burning source of ammonium. J Geophys Res$705 \quad$ Atmos 119, 9168-9182 (2014).

70654 Abram, N. J., Mulvaney, R. \& Arrowsmith, C. Environmental signals in a highly resolved ice 707 core from James Ross Island, Antarctica. J Geophys Res-Atmos 116, D20116, doi:

$708 \quad 10.1029 / 2011 j d 016147$ (2011).

70955 Kaufmann, P. R. et al. An Improved Continuous Flow Analysis System for High-Resolution $710 \quad$ Field Measurements on Ice Cores. Environ Sci Technol 42, 8044-8050 (2008).

$71156 \quad$ Bigler, M. et al. Optimization of High-Resolution Continuous Flow Analysis for Transient 712 Climate Signals in Ice Cores. Environ Sci Technol 45, 4483-4489 (2011). 
71357 Ruth, U., Wagenbach, D., Steffensen, J. P. \& Bigler, M. Continuous record of microparticle

714 concentration and size distribution in the central Greenland NGRIP ice core during the last

715 glacial period. J Geophys Res-Atmos 108, doi: 10.1029/2002jd002376 (2003).

71658 Woodruff, T. E., Welten, K. C., Caffee, M. W. \& Nishiizumi, K. Interlaboratory comparison of Be-10 concentrations in two ice cores from Central West Antarctica. Nucl Instrum Meth B 294, 77-80 (2013).

719

59

Berggren, A. M. et al. Variability of Be-10 and delta O-18 in snow pits from Greenland and a surface traverse from Antarctica. Nucl Instrum Meth B 294, 568-572 (2013).

Bisiaux, M. M. et al. Changes in black carbon deposition to Antarctica from two highresolution ice core records, 1850-2000 AD. Atmos Chem Phys 12, 4107-4115 (2012). Antarctic ice cores during the Little Ice Age linked to changes in atmospheric nitrate and sea salt concentrations. J Geophys Res-Atmos 119, 5640-5652 (2014). ice core. Clim Past 9, 2713-2730 (2013). cores. J Geophys Res-Atmos 117, D21303, doi: 10.1029/2012jd017698 (2012). 1221-1232 (2013). Greenland Ice Core Project and Dye 3 Greenland Ice Cores. J Geophys Res-Oceans 102, 26707-26723 (1997).

73566 Rolandi, G., Paone, A., Di Lascio, M. \& Stefani, G. The 79 AD eruption of Somma: The relationship between the date of the eruption and the southeast tephra dispersion. $J$ Volcanol Geoth Res 169, 87-98 (2008). 
73867 Sun, C. Q. et al. Ash from Changbaishan Millennium eruption recorded in Greenland ice:

739 Implications for determining the eruption's timing and impact. Geophys Res Lett 41, 694-701

740 (2014).

$74168 \mathrm{Xu}, \mathrm{J}$. D. et al. Climatic impact of the Millennium eruption of Changbaishan volcano in China:

$742 \quad$ New insights from high-precision radiocarbon wiggle-match dating. Geophys Res Lett 40, 54-

743 (2013).

74469 Deirmendjian, D. On volcanic and other particulate turbidity anomalies. Advances in

$745 \quad$ Geophysics 16, 267-296 (1973).

$74670 \quad$ Vollmer, M. Effects of absorbing particles on coronas and glories. Appl Optics 44, 5658-5666

747 (2005).

74871 Sachs, A. J. \& Hunger, H. Astronomical diaries and related texts from Babylonia. Volume 3:

749 Diaries from 164 B.C. to 61 B.C. Wien: Verlag der Österreichischen Akademie der

$750 \quad$ Wissenschaften (1996).

75172 Wittmann, A. D. \& Xu, Z. T. A Catalog of Sunspot Observations from 165 Bc to Ad 1684.

752 Astron Astrophys Sup 70, 83-94 (1987).

75373 Rasmussen, S. O. et al. A new Greenland ice core chronology for the last glacial termination.

754 J Geophys Res-Atmos 111, D06102 doi: 10.1029/2005jd006079 (2006).

75574 Herron, M. M., Herron, S. L. \& Langway, C. C. Climatic Signal of Ice Melt Features in Southern $756 \quad$ Greenland. Nature 293, 389-391 (1981).

75775 Gao, C. H., Oman, L., Robock, A. \& Stenchikov, G. L. Atmospheric volcanic loading derived 758 from bipolar ice cores: Accounting for the spatial distribution of volcanic deposition. J 759 Geophys Res-Atmos 112, D09109, doi: 10.1029/2006jd007461 (2007).

76076 Briffa, K. R. et al. Reassessing the evidence for tree-growth and inferred temperature change 761 during the Common Era in Yamalia, northwest Siberia. Quaternary Sci Rev 72, 83-107 (2013). 
77 Grudd, H. Tornetrask tree-ring width and density AD 500-2004: a test of climatic sensitivity

763 and a new 1500-year reconstruction of north Fennoscandian summers. Clim Dynam 31, 843-

$764857(2008)$.

76578 Salzer, M. W., Bunn, A. G., Graham, N. E. \& Hughes, M. K. Five millennia of

766 paleotemperature from tree-rings in the Great Basin, USA. Clim Dynam 42, 1517-1526

767 (2014).

76879 McMahon, S. M., Parker, G. G. \& Miller, D. R. Evidence for a recent increase in forest growth.

$769 \quad$ P Natl Acad Sci USA 107, 3611-3615 (2010).

$77080 \quad$ Salzer, M. W., Hughes, M. K., Bunn, A. G. \& Kipfmueller, K. F. Recent unprecedented tree-

771 ring growth in bristlecone pine at the highest elevations and possible causes. P Natl Acad Sci

772 USA 106, 20348-20353 (2009).

$77381 \quad$ Briffa, K. R. et al. Reduced sensitivity of recent tree-growth to temperature at high northern

$774 \quad$ latitudes. Nature 391, 678-682 (1998).

77582 Rohde, R. et al. A New Estimate of the Average Land Surface Temperature Spanning 1753 to

776 2011. Geoinfor Geostat: An Overview 1, doi: 10.4172/2327-4581.1000101 (2013).

77783 Mass, C. F. \& Portman, D. A. Major volcanic eruptions and climate: A critical evaluation. J.

$778 \quad$ Climate 2, 566-593.

77984 Fritts, H. C., Lofgren, G. R. \& Gordon, G. A. Variations in Climate since 1602 as Reconstructed 780 from Tree Rings. Quaternary Res 12, 18-46 (1979).

78185 Jensen, B. J. L. et al. Transatlantic distribution of the Alaskan White River Ash. Geology 42, $782 \quad 875-878(2014)$.

78386 Oskarsson, N., Sigvaldason, G. E. \& Steinthorsson, S. A Dynamic-Model of Rift-Zone 784 Petrogenesis and the Regional Petrology of Iceland. J Petrol 23, 28-74 (1982).

78587 Kuehn, S. C., Froese, D. G., Shane, P. A. R. \& Participants, I. I. The INTAV intercomparison of 786 electron-beam microanalysis of glass by tephrochronology laboratories: Results and 787 recommendations. Quatern Int 246, 19-47 (2011). 
$788 \quad 88$ Kaufman, D. S. et al. Late Quaternary tephrostratigraphy, Ahklun Mountains, SW Alaska. J

789 Quaternary Sci 27, 344-359 (2012).

79089 Lakeman, T. R. et al. Holocene tephras in lake cores from northern British Columbia, Canada.

$791 \quad$ Can J Earth Sci 45, 935-947 (2008).

79290 Bursik, M., Sieh, K. \& Meltzner, A. Deposits of the most recent eruption in the Southern

793 Mono Craters, California: Description, interpretation and implications for regional marker

794 tephras. J Volcanol Geoth Res 275, 114-131 (2014).

79591 Sampson, D. E. \& Cameron, K. L. The Geochemistry of the Inyo Volcanic Chain - Multiple

796 Magma Systems in the Long Valley Region, Eastern California. J Geophys Res-Solid 92, 10403-

$797 \quad 10421(1987)$.

79892 Veres, D. et al. The Antarctic ice core chronology (AICC2012): an optimized multi-parameter

799 and multi-site dating approach for the last 120 thousand years. Clim Past 9, 1733-1748

800 (2013).

80193 Siebert, L., Simkin, T. \& Kimberly, P. Volcanoes of the World. 3rd edn, University of California $802 \quad$ Press (2010).

803

804 Extended Data Figure 1 | Location of study sites. a) Map showing locations of the five ice-cores 805 (WDC, B40, NEEM, NGRIP and TUNU) used in this study. Sites of temperature-limited tree-ring

806 chronologies (green) ${ }^{42,43,76-78}$ and sites with annual $\Delta^{14} \mathrm{C}$ measurements from tree-rings in the $8^{\text {th }}$

807 century CE (red outline) are marked; b) metadata for the ice cores, tree-ring chronologies and

808 temperature reconstructions used.

809 Extended Data Figure 2 | Volcanic dust veils from historical documentary sources in relation to

810 NEEM. Time series of 32 independently-selected chronological validation points from well-dated

811 historical observations of atmospheric phenomena with known association to explosive volcanism

812 (e.g., diminished sunlight, discolored solar disk, solar corona or Bishop's Ring, red volcanic sunset) as 
reported in the Near East, Mediterranean region, and China, prior to our earliest chronological age marker at $536 \mathrm{CE}$. Black lines represent the magnitude (scale on vertical y-axes) of annual sulfate deposition measured in NEEM (NEEM and NEEM-2011-S1 ice cores) from explosive volcanic events on the new NS1-2011 timescale. Red crosses depict the 24 (75\%) historical validation points for which NEEM volcanic events occur within a conservative \pm 3 year uncertainty margin. Blue crosses represent the eight points for which volcanic events are not observed. The association between validation points and volcanic events is statistically significantly non-random at $>99.9 \%$ confidence.

Extended Data Figure 3 | Timescale comparison. Age differences of the timescales a) NS1-2011 and GICC05 for the NEEM-2011-S1/NEEM ice cores and b) WD2014 and WDC06A-7 for WDC. Differences before 86 CE (the bottom age of NEEM-2011-S1) deriving from the annual-layer counting of the NEEM core are shown for major volcanic eruptions relative to the respective signals in NGRIP on the annual-layer counted GICC05 timescale. Marker events used for constraining the annual-layer dating (solid line) and for chronology evaluation (dashed lines) are indicated. Triangles mark volcanic signals. Also indicated is the difference between WD2014 and the Antarctic ice-core chronology $(\text { AICC2012) })^{92}$, based on volcanic synchronization between the WDC and EDC96 ice cores.

Extended Data Figure 4 | Post-volcanic suppression of tree growth. Superposed epoch analysis for large volcanic eruptions using the a) 28 largest volcanic eruptions; b) 23 largest tropical eruptions; c) five largest NH eruptions; and d) eruptions larger than Tambora 1815 with respect to sulfate aerosol loading. Shown are growth anomalies of a multi-centennial tree-ring composite record (N-Tree) 15 years after the year of volcanic sulfate deposition, relative to the average of five years before the events. Dashed lines indicate 95\% confidence intervals (2 SEM) of the tree-ring growth anomalies associated with the multiple eruptions.

\section{Extended Data Figure 5 | Major element composition for ice core tephra QUB-1859 and reference} material. Shown are selected geochemistry data: (a) $\mathrm{SiO}_{2}$ vs. total alkali $\left(\mathrm{K}_{2} \mathrm{O}+\mathrm{Na}_{2} \mathrm{O}\right)$; b) $\mathrm{FeO}$ (total iron oxides) vs. $\mathrm{TiO}_{2}$; c) $\mathrm{SiO}_{2}$ vs. $\mathrm{Al}_{2} \mathrm{O}_{3}$; and d) $\mathrm{CaO}$ vs. $\mathrm{MgO}$ ) from 11 shards extracted from the NEEM- 
2011-S1 ice core between 327.17 and $327.25 \mathrm{~m}$ depth, representing the age range 536.0-536.4 CE

on the new, NS1-2011 timescale. Data for Late Holocene tephra from Mono Craters (California) are

840 from the compilation by ref. 90 (all references in Methods); data for Aniakchak (Alaska) are from

reference material published by ref. 88; and data for the early Holocene upper Finlay tephra ,

believed to be from the Edziza complex in the Upper Cordilleran Volcanic province (British

843

Columbia), are from ref. 89.

Extended Data Table 1 | Ice-core dating. Parameters used for annual-layer interpretation.

Parameters measured by the CFA system in the field are underlined. Stratigraphic age marker used to constrain annual-layer counting $\left({ }^{*}\right)$ and horizons used to evaluate the timescale $(\dagger)$.

\section{Extended Data Table 2 | Annual-layer results using the StratiCounter program. Maximum-}

*UE: Unattributed volcanic signal and year of sulfate deposition based on final age models (negative numbers are Year BCE).

+Year (BCE/CE) calculated from the number of annual layers relative to the fixed age marker in $\mathbf{7 7 5}$

CE.

¥Depth has been estimated from the average depth offset between NEEM-2011-S1 and NEEM.

§Fixed age marker based on the 10Be maximum annual value.

856 ||Section with $6 \mathrm{~m}$ gap in the NEEM 2011-S1 core DRI data (this section is not used for calculating

857 average age).

858 I This section is based on the NEEM field CFA data, since the DRI data does not cover the entire

859 interval.

860 \# Section is based on combined data set of DRI and field-measured CFA data. The number of annual

861 layers in this section from manual interpretation by investigator 1 was $383( \pm 7)$, and that of 
investigator 2 was $393( \pm 8)$ layers. Most of the difference between the three layer counts was occurring below $480 \mathrm{~m}$ (i.e., before $300 \mathrm{BCE}$ ), where data gaps were more frequent.

诂Independent age markers used to constrain annual-layer dating in a second iteration to derive the final ice-core age model NS1-2011.

**Tephra particles were extracted from the depth range 327.17-327.25 m depth (see Supplementary Data).

++Unattributed volcanic signal that was previously attributed to the historic 79 CE eruption of Vesuvius ${ }^{64}$.

\section{Extended Data Table 3 | Historical documentary evidence for key volcanic eruption age markers}

536-939 CE. A comprehensive list of all sources, including translations and assessment of the confidence placed in each source and its chronological information is given in Supplementary Data.

Extended Data Table 4 | Large volcanic eruptions during the past 2,500 years. Years with negative numbers are before the Common Era (BCE). Tentative attribution of ice-core signals to historic volcanic eruptions is based on the Global Volcanism Program volcanic eruption database ${ }^{93}$. Average (summer) temperature for the associated cold year is given for the average of Europe and the Arctic $^{3}$

${ }^{*}$ Total global aerosol forcing was estimated by scaling total sulfate flux from both polar ice sheets to the reconstructed total (i.e., time integrated) aerosol forcing for Tambora $1815^{7}$ (Methods); for high latitude $\mathrm{NH}$ eruptions, Greenland fluxes were scaled by a factor of $0.57^{6}$.

† Unattributed volcanic events (UE) and tentative attributions for non-documented historic eruptions (?) are marked.

Extended Data Table 5 | Post-volcanic cooling. Coldest years and decades (1-2000 CE, JJA temperature wrt. 1901-2000) for Europe ${ }^{3}$ and years (500 BCE-1250 CE) and decades (500 BCE-2000 CE) with strong growth reduction in the N-Tree composite( wrt. 1000-1099). Ages of the volcanic 
887 timescale) with the largest 40 events indicated in bold letters and tropical eruptions underlined.

888 Years with negative numbers are before the Common Era (BCE).

$889 *$ Latewood frost ring in bristlecone pines within \pm 1 year ${ }^{34}$. 


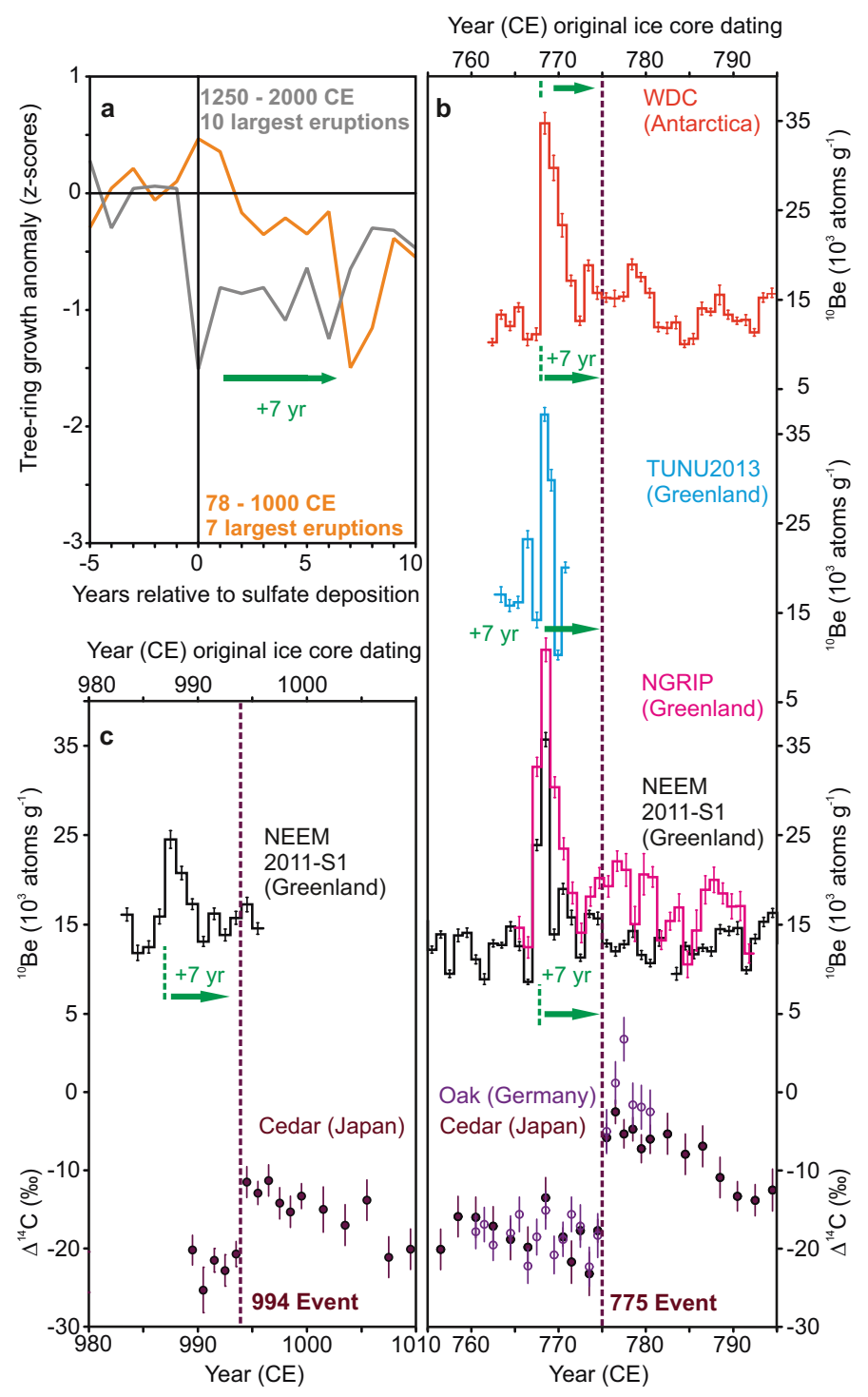




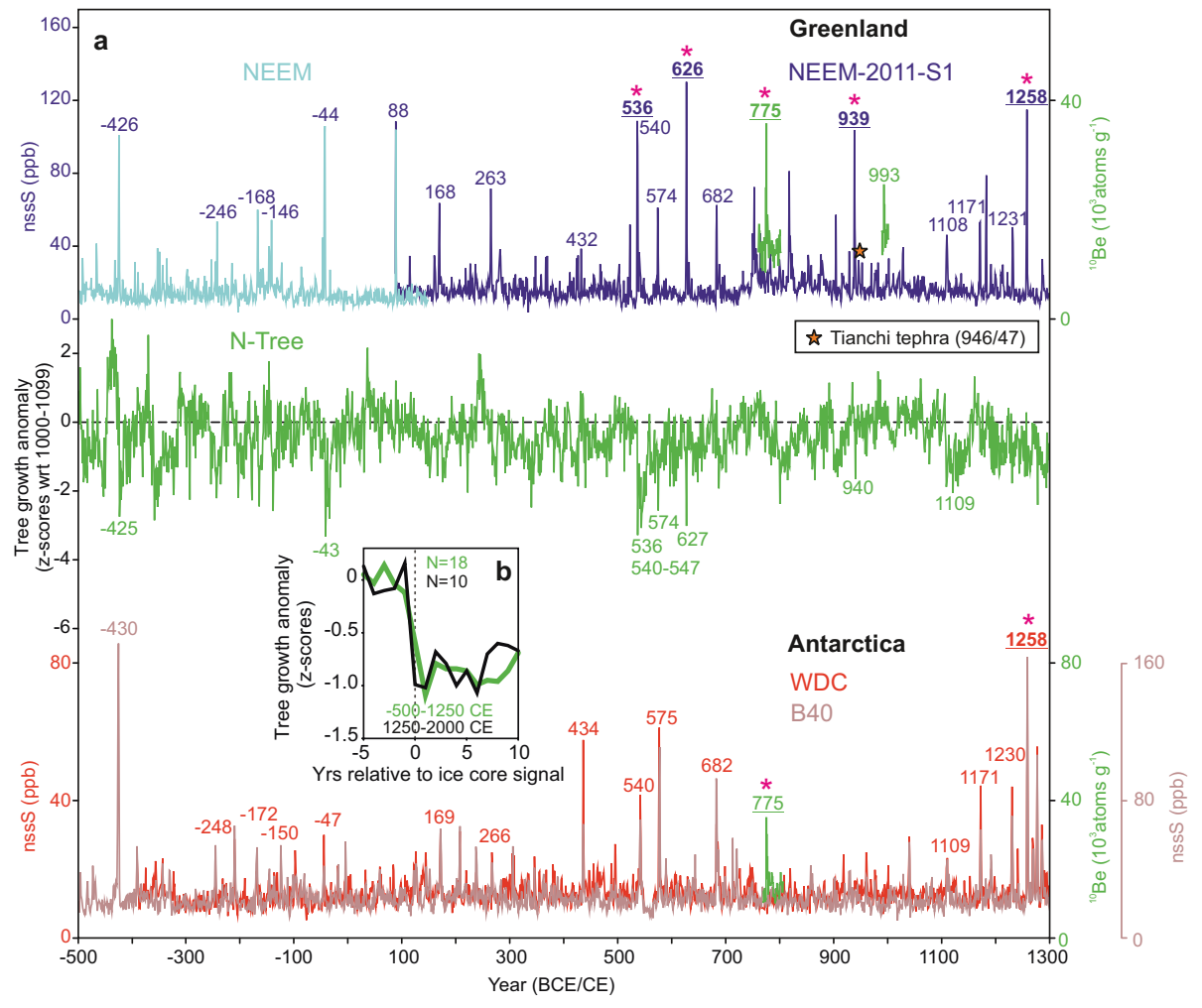




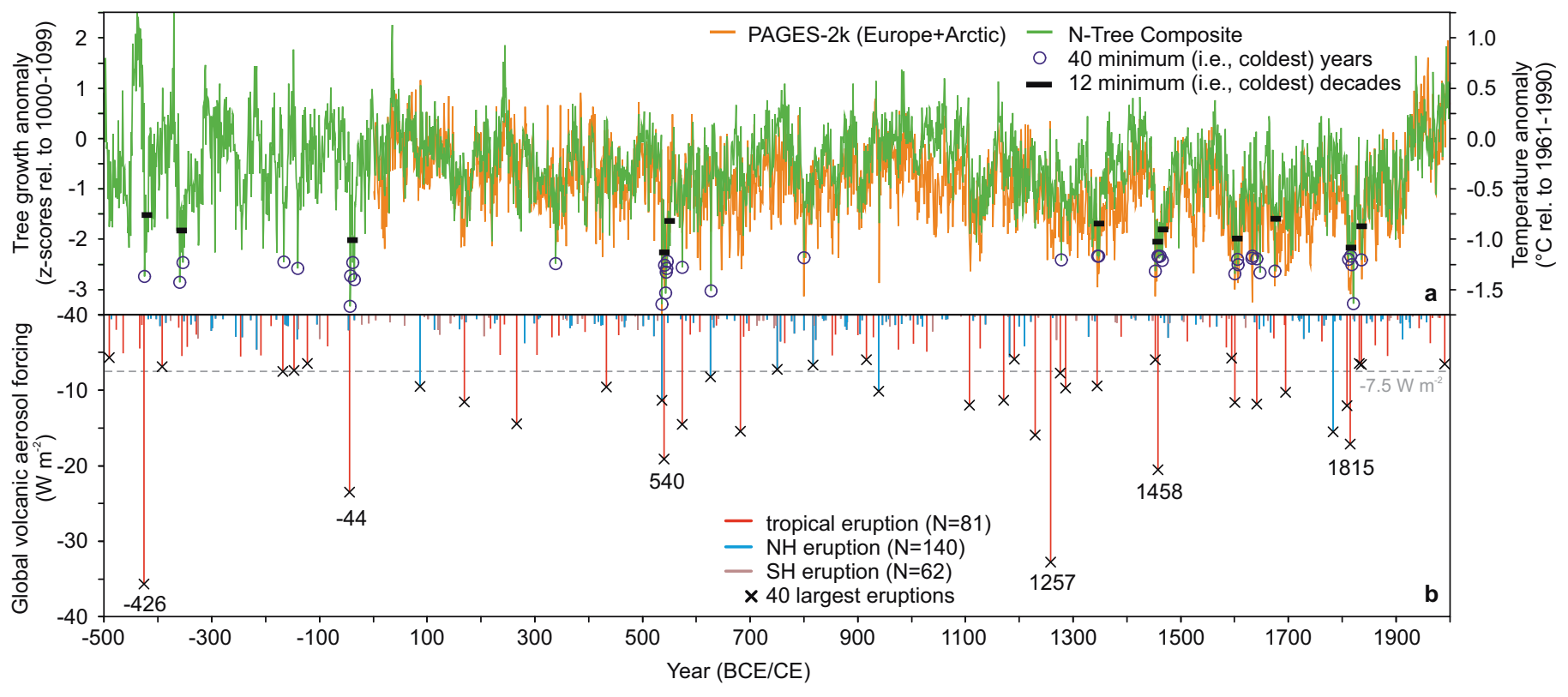



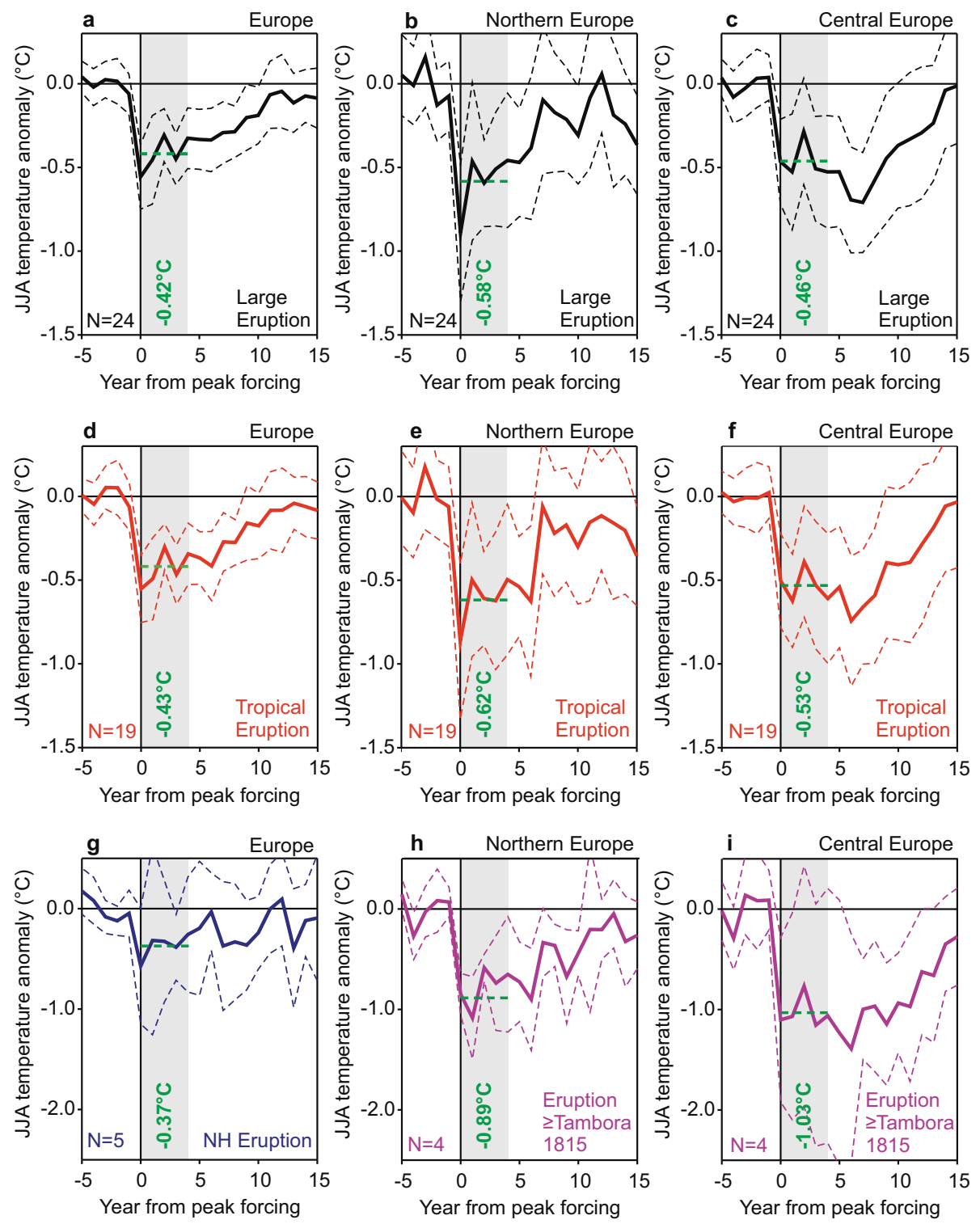


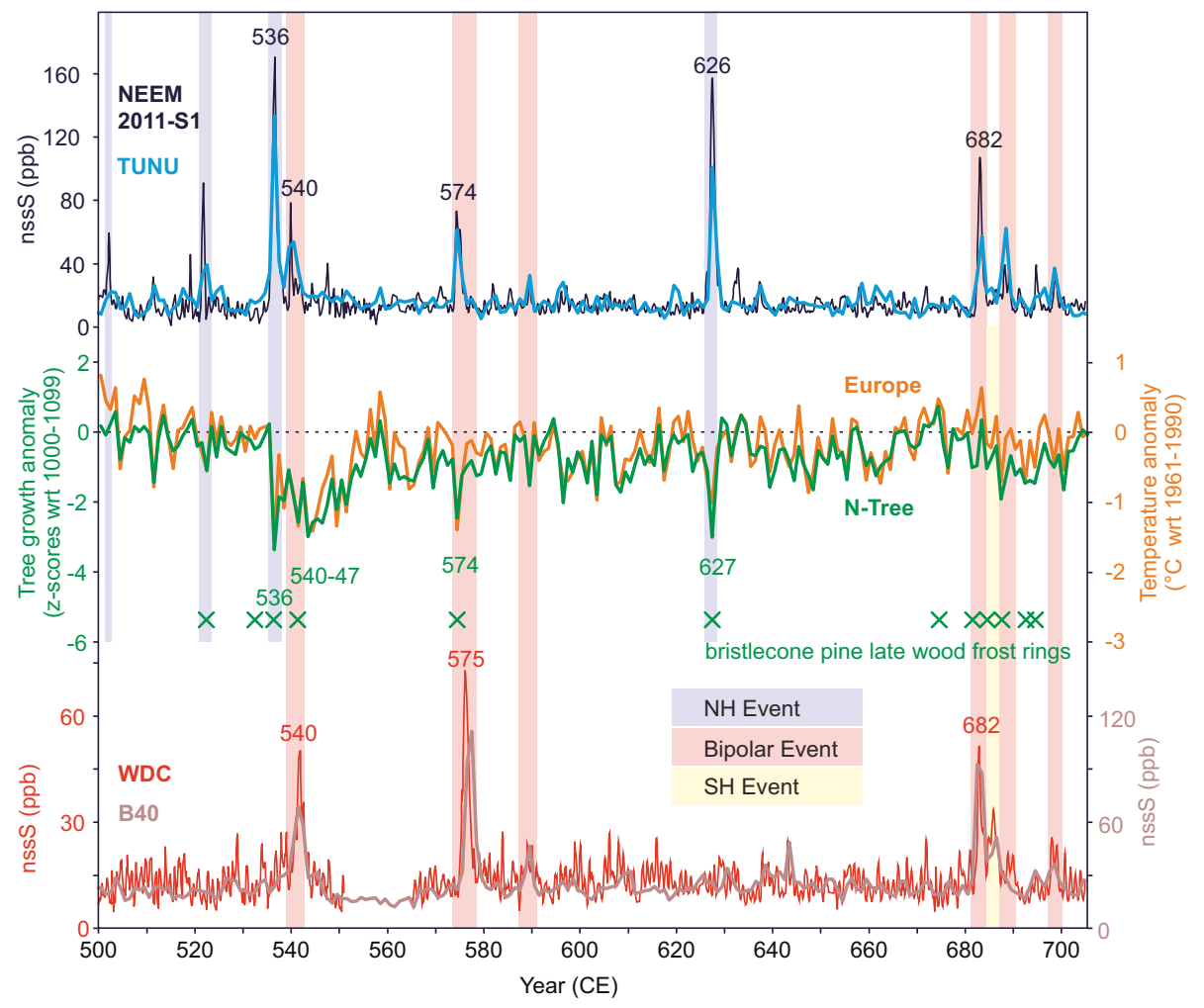

